\title{
Comparative lexicology and the typology of event descriptions: a programmatic study
}

\section{Volker Gast, Ekkehard König \& Claire Moyse-Faurie}

\section{Introduction*}

It is a well-known fact that the vocabularies of individual languages are structured very differently. Even if it is always possible to translate a certain utterance from one language into another, it is rarely, if ever, possible to say that all or even some lexemes making up an utterance in one language correspond perfectly and completely to the lexemes rendering that utterance in another. In most cases the content cut out from the amorphous mass of notions and ideas by one lexeme A may be similar to the content identified by some translational counterpart in another, but there is hardly ever complete identity and what we find is partial overlap at best. The consequence of this basic observation for structuralists was that semantic analysis in one language amounts to describing the structural relations between the lexemes of a language in terms of oppositions (antonymy, complementarity, converseness, etc.), super- and subordination, meronymy, etc. (cf. Lyons 1972, Cruse 1986, Löbner 2002, etc.), and that comparative semantics or comparative lexicology is nothing more than a comparison between these networks of structural relations.

More recent theorizing about semantics, specifically the idea of semantic decomposition in terms of hierarchical structures ("decompositional event seman-

\footnotetext{
* In the publications of Sebastian Löbner, to whom we dedicate this article on the occasion of his 65th birthday, comparative studies on lexicology and meaning have played a considerable role (see for instance Löbner 2002: 153, ff. or Löbner 2011). We would like to thank two anonymous reviewers for their critical comments and valuable suggestions.
} 
tics"), typically associated with the generative paradigm, or the ideas associated with the basic assumptions of Cognitive Linguistics, is less agnostic about the semantic or propositional substance underlying the vocabularies of individual languages and has led to a wide variety of comparative studies in semantics or lexicology, ${ }^{1}$ and even to attempts at formulating lexical typologies. These studies agree with the structuralist view that each language carves up conceptual space in a different manner, but - in clear analogy to morpho-syntactic typology - the cuts are assumed not to be completely random and not to differ without limits. What we find, then, are two extreme views and several shades of grey in between. On the one extreme, there is the view that there are innate lexical concepts and constraints arising from the structure of the mind or the world. The other extreme is the view that languages differ arbitrarily in their semantic organization of conceptual domains. The middle ground is held by positions which accord some role to biases in perception and cognition as well as to communicative constraints and cultural practices, still underlining the importance and necessity of arbitrary linguistic conventions (cf. Narasinhan et al. 2012).

A closer look at the lexical typologies currently available reveals the difficulties and limits of such cross-linguistic lexical studies. Combining onomasiological and semasiological perspectives, they are typically based on ontological domains easily identifiable across languages (e.g. body parts, colors, temperatures, possession, kinship terminology, motion, perception, eating, placing and displacing, etc.), on comparatively small samples of languages, or on both. There is a bias towards nominal or adjectival denotations, a bias which can also be observed in fieldwork on lesser described languages (cf. Evans 2011a on the neglect of verbs in elicitation, as well as some reasons for it). Moreover, the typological distinctions are not really analogous to those developed for morpho-syntactic properties. In most cases, gradual rather than clear-cut distinctions, e. g. more or fewer lexical differentiations found for kinship relations or for hair on humans vs. animals, on heads vs. bodies, etc. (cf. Koch 2001), are described for comparable lexical subsystems of different languages, and only very rarely do we find implicational generalizations (such as the well-known hierarchy of basic color terms from Berlin \& Kay 1969), and even more rarely connections between different variant properties.

How can the search for cross-linguistic generalizations in the lexicons overcome these difficulties and limitations and go beyond contrastive or comparative

1 Cf. the special issue of Linguistics, 50.3, 2012, edited by M. Koptjevskaya-Tamm and M. Vanhove for a recent survey, especially the introduction (Koptjevskaya-Tamm 2012). 
studies of a few lexical subsystems? In the current state of the art we can see two promising approaches in pursuit of this goal. The first one, clearly delineated in a recent handbook article by N. Evans (Evans 2011b), abstracts from specific notional domains and their encoding in lexical subsystems, for the benefit of generalizations of a higher order. The major generalizations made in Evans (2011b) are formulated not so much in terms of lexical subsystems but in terms of four general properties of nominal denotations or event descriptions: We find differences in the GRANULARITY of lexical distinctions, in the BOUNDARIES between lexical categories, in the GROUPING and the DISSECTION of semantic components.

The parameter of 'granularity' concerns the degree of 'ramification' in a meronymical tree. For example, English makes a distinction between branch and twig, which is not made in other languages (e.g. Georgian, which only has t'ot'i for both 'branch, twig'). With respect to the location of boundaries between subcomponents of an object, Evans (2011b:512) points out that "the Savosavo 'leg' category begins at the hip joint (and encompasses the foot), whereas Tidore yohu - roughly, 'leg' - cuts off three-quarters of the way up to the thigh".

In addition to different organizations of meronymical systems (part-whole relations), cross-linguistic differences can also be observed in the level of generality at which a given category is located ('grouping', in terms of Evans 2011b). As an example of 'grouping' in the domain of body-parts, Evans (2011b) considers terms for 'finger' and 'toe'. English does not have a cover term for these body parts. Other languages, by contrast, do not distinguish lexically between them. For instance, Serbo-Croatian uses the same term for fingers and toes (prst), as does Spanish (dedo). While being located at different parts of the body as far as meronymical organization is concerned, these languages 'group' them together because of their similarities with respect to their position, form, function, etc. Evans's parameter of 'dissection', finally, concerns the ways in which "complex phenomena are decomposed into parts" (Evans 2011b: 514). One of the most frequently cited examples of using dissection for typological distinctions is the wellknown typology for verbs of motion developed by Talmy $(1985,2000)$.

Based on the inspiration of such work, which has only been characterized here in its basic outlines, lexical typology can now ask very ambitious questions such as: What aspects or components of verbal meanings are typically lexicalized across languages? What differentiations are found, and what types of generalizations can we make? What are possible and impossible verbal meanings? For instance, can the hypothesis of Manner/Result complementarity made by Levin \& 
Rappaport Hovav (e. g. Levin \& Rappaport Hovav 1991, 2006, 2013, Rappaport Hovav \& Levin 2010) be defended against recent criticism, brought forward inter alia by Beavers \& Koontz-Garboden (2012) and Husband (2011) ${ }^{2}$ Do new data from lesser described languages confirm or falsify such hypotheses? These are the questions guiding our investigation, which we carry out with the objective of identifying cross-linguistic tendencies and generalizations over the ways in which languages lexicalize event descriptions.

Our generalizations will be formulated in terms of hierarchies, ${ }^{3}$ the format typically used by typologists. The study is exploratory insofar as it is also limited in its empirical scope and programmatic as it points out possible avenues for future typological research, rather than presenting well-founded cross-linguistic generalizations.

As far as the empirical basis of our study is concerned, we have partly selected domains known to manifest differential degrees of generality at least in two languages on the basis of previous work. As far as languages are concerned, we have primarily selected our native tongues as well as languages one of us has studied in detail. The starting point is invariably provided by observations on clear distinctions in the lexical organization of certain conceptual domains. Attempts to find the counterpart of certain verbs like eat, cut, kill, beat, for instance, reveal that some languages have a wide variety of possible translations depending on event parameters (like properties of Agents and/or Patients) which play no role in English and these languages may even lack a general term such as we find in English.

We start with some theoretical background assumptions that are needed for a lexical typology of verb meanings (Section 2). In Sections 3 and 4, we present some case studies, i.e., comparisons of verbal inventories for the domains of eating and drinking (Section 3), and for verbs of physical impact (Section 4), i. e., verbs of killing, beating and cutting. Section 5 contains some thoughts on possible explanations for the patterns and limits of variation that we can observe. Section 6 provides a summary and the conclusions.

\footnotetext{
2 For a recent publication supporting the Manner/Result complementarity hypothesis, see Alexiadou \& Anagnostopoulou (2013).

3 Since only two features will be ranked at a time, the term 'hierarchy' is strictly speaking unjustified. The predictions associated with more extended scales would be far too strong and too easily falsifiable at the current state of our knowledge.
} 


\section{Aspects of event descriptions}

In keeping with basic assumptions of Davidsonian event semantics, we regard events as entities with the same ontological status as objects. Like objects, events can thus be predicated over, i. e., they can have properties. We can distinguish different types of properties of events. The most 'essential' property is the one that makes an event what it is. Consider the example in (1).

(1) The Tacoma Narrows Bridge collapsed slowly in 1940.

The property of being a 'collapse' - more specifically, the collapse of the Tacoma Narrows Bridge - is the 'most essential' property of the event described in (1). It is a matter of debate to what extent event predicates are conceivable without participants. Can a 'collapsing event' be imagined without having information about the (type of) entity that collapses, e. g. a bridge, a house or a man? We would not like to take a stance in this matter, but we will make a terminological distinction between 'bare' and 'saturated' event descriptions. We adopt the term 'lexicalized meaning' from Levin \& Rappaport Hovav (2013), which is "taken to comprise a verb's core meaning", and which is defined on the basis of "constancy of entailment across all uses of verbs" (Levin \& Rappaport Hovav 2013: 1). In the case of the verb collapse, the lexicalized meaning could be described as 'to fall together ... by external pressure or withdrawal of the contents' or 'by loss of rigidity or support ...' (OED, s.v. collapse). Unsaturated verbs, accordingly, are taken to denote 'lexical predicates'.

More specific event types emerge when the participants of a given event are specified. The collapse of a bridge or house is more easily imaginable than an event of collapsing that abstracts away from the participants involved. Event predicates together with their core arguments will be called 'saturated'.

In the case of (1), the saturated predicate (describing the collapsing of a bridge) is modified by the adverb slowly, which can be regarded as an additional attribute of the event in question (the type of modification is intersective). Moreover, this event is attributed the property of having taken place in 1940. Another type of property that can be predicated of an event is, obviously, the place at which it takes place.

In Davidsonian event semantics, the referential argument of a verbal predicate - the events - is represented with a variable $e$. The lexical predicate of an event is simply represented as a predicate which is said to be true of the relevant event (e. g. COllapse(e)). Additional specifications like slowly are represented in the 
same way (sLow(e)). In a Neo-Davidsonian framework (cf. Parsons 1990), participants are regarded as entities that stand in a thematic relation to the event argument $e$. For example, in (1) there is one argument/participant, i. e., the Tacoma Narrows Bridge. This bridge can be regarded as a Patient of the event in question (participant roles are capitalized). Moreover, the event is said to have taken place in 1940 (i. e., the time of the event $t_{e}$ is fully included in the time span corresponding to the year $\left.1940, t_{1940}\right)$. The meaning of (1) can thus be represented as shown in (2).

(2) $\exists$ e [Collapse $\left.(e) \wedge \operatorname{Patient}(T N B, e) \wedge \operatorname{slow}(e) \wedge t_{e} \subset t_{1940}\right]$

'There is an event $e$ such that $e$ is a collapsing event, the Tacoma Narrows

Bridge (TNB) is the Patient of $e, e$ is slow and the temporal extension of $e$ is fully included in the temporal extension of the year 1940.'

Event predicates furthermore differ in terms of parameters relating to matters of aktionsart or actionality. In particular, event descriptions often differentiate in accordance with the Result of the event in question. Such specifications mostly concern properties of either the Theme or Patient as in (3) (more generally speaking, of the Undergoer of an event; cf. Van Valin \& LaPolla 1997), or the Agent (or 'Actor', in terms of Van Valin \& LaPolla 1997), as in (4).

(3) The thief was shot dead.

(4) John overate.

We can thus distinguish between Agent-related and Patient-related Results, and we will make that distinction whenever necessary. Agent-related Results will

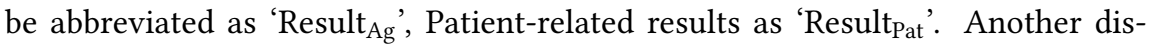
tinction that is important to make is the one between 'category-level' and 'verbspecific' Results. Category-level results are lexical entailments associated with major classes of verbs. For example, verbs of killing lexically imply the death of a protagonist, verbs of eating imply that food is consumed and verbs of cutting imply an "incision with clean edges" (Levin \& Rappaport Hovav 2013: 5). In addition to such category-level Results, verb-specific ones may be encoded as well. For instance, slice, in addition to entailing an incision with clean edges (by virtue of being a verb of cutting) implies that the Patient is divided into parts with a specific shape (slices). In the following, we will only be concerned with verb-specific Results.

Just as (dynamic) events are often characterized by a Result (or 'post-state'), some predicates inherently come with an event type preceding the event in ques- 
tion (a 'pre-state'). In particular, verbs of action (such as intentional killing) are by definition preceded by a decision or, more generally speaking, a Motivation (a specific type of Cause). Such events can thus often (minimally) be regarded as sequences of a Motivation, a sub-event which is characteristic of the entire class and a Result.

Neo-Davidsonian semantics does not distinguish 'layers' of meaning (as, for instance, in Functional Grammar, cf. Dik 1997), but represents the various aspects of event descriptions simply as conjunctions. For our study it will be useful, however, to distinguish between 'more intrinsic' and 'more extrinsic' properties of events. The lexical predicate is the most intrinsic property, as it provides the basic unit of categorization at a rather abstract level. The core participants (Agent and Patient) are required by the lexical predicate, i. e., an event is not conceivable without them and they render it 'imagineable'. The Motivation and the Result are closely associated with the core participants and are therefore located at the same level as the latter. Manners and Instruments provide additional, more peripheral specifications. The Time and Place at which an event takes place, finally, is 'extrinsic' insofar as (in most cases) the same type of event can be thought of as taking place at another Time or Place. The 'layered' structure of a predication emerging from these considerations is shown in (5).

(5)

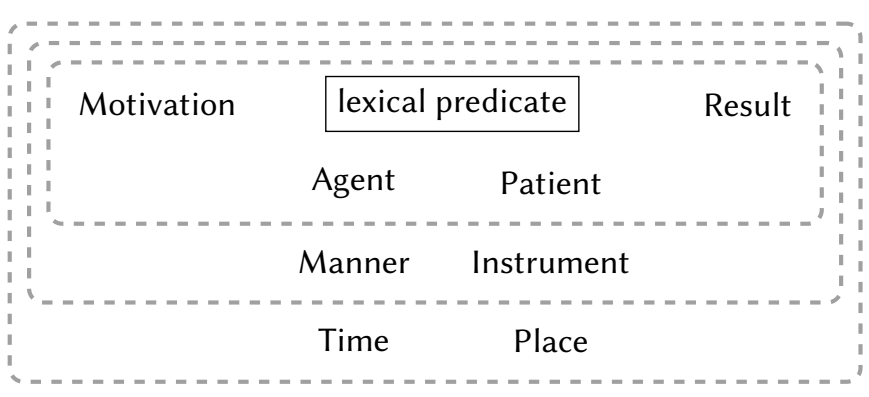

Among the parameters of event descriptions summarized in (5), two have played a very prominent role in recent theoretical discussion of verb semantics. Among the many authors contributing to this topic we will only single out Levin \& Rappaport Hovav, who in a large number of publications (e. g. Levin \& Rappaport Hovav 1991, 2006, 2013, Rappaport Hovav \& Levin 2010) have formulated, discussed and defended a constraint on possible verb meanings, which will also provide an important point of orientation for our study. They make the following claim of Manner/Result complementarity: 
(i) Manner/Result complementarity: Manner and result meaning components are in complementary distribution: A verb may lexicalize only one.

This generalization and constraint draws a distinction between two broad classes of verbs: (a) Manner verbs (e. g. hit, run, sweep, bite, caress, cook), and (b) Result verbs (e.g. cut, arrive, clean, swallow, open). More recent work on verbs of motion (Beavers et al. 2010) has shown that the distinction identified by Talmy (1985, $2000)$ is one specific manifestation of this more general distinction. Given that the hypothesis of Manner/Result complementarity has played a prominent role in the recent discussion, we will refer to it whenever relevant observations can be made.

\section{Verbs of eating and drinking}

\subsection{The basic parameters of variation}

We will begin our comparison with the English verbs eat and drink, since it has been pointed out that these verbs and their counterparts in other languages often manifest remarkable properties and do not behave like ordinary transitive verbs (cf. Naess 2011). Our data shows that all of the properties of events shown in (5) above may be lexicalized in verbs of eating and drinking in specific languages and that languages may differ with respect to these lexical components. A first type of variation concerns selectional restrictions on the Agent and the Patient. For the Agent, some languages have different verbs for humans and animals. German is of this type, as it distinguishes between essen (human) and fressen (animals) for eating, and between trinken (humans) and saufen (specific animals ${ }^{4}$ ) for drinking. English does not make any such distinction and uses eat and drink for animals alike. In an extended sense, Germ. fressen and saufen can also be used with human subjects if the Manner of food consumption (quantity, noise produced, etc.) is more like that associated with animals (Karl frisst wie ein Schwein 'Karl eats like a pig').

Much more variation can be found when we consider selectional restrictions on the Patient. Note first that the basic verbs of English - eat and drink - already exhibit selectional restrictions insofar as they can only be used with (more or less solid) food and liquids, respectively. Some languages (e. g. Kalam, Walpiri) have only one verb for both activities (cf. Wierzbicka 2009, Naess 2011:415), roughly

\footnotetext{
4 An anonymous reviewer pointed out to us that saufen would not be used with mice, birds and other
} types of (smaller) animals. 
corresponding to the English expression 'take in/consume food/liquid'. In East Uvean, there is a honorific term (when one speaks to/of the king) for both types of activity, i. e. taumafa, but there are two different terms in the ordinary language (inu 'drink' and kai 'eat').

It is sometimes difficult to determine whether it is primarily the Manner of consumption or the type of food consumed that is lexicalized. For example, Japanese uses taberu/tabemasu for solid food and nomu for liquid food (e.g. soups), but Löbner (2002: 232) has pointed out that nomu also combines with all kinds of medicine, including pills. Accordingly, nomu seems to be associated with events of ingestion that do not imply chewing. ${ }^{5}$

In many languages differentiation of verbs according to the substance of what is consumed is taken much further, and there are even languages that have no generic eating verb of the type commonly found in European languages. Navajo has different verb stems for eating hard, compact things, leafy things, meat, marrow and mushy things, among others (cf. Rice 2009). A particularly rich inventory of lexical differentiations depending on the type of food taken in is found in East Futunan (cf. Moyse-Faurie 1993). Some examples of highly specific root meanings are given in (6). A remarkable phenomenon in this language is also the differentiations drawn between eating certain food alone or in combination with other dishes, as in (6b). We will return to such differentiations in Section 3.2, where some particularly interesting differentiations found in Melanesian and Polynesian languages are discussed.

(6) East Futunan
a. fono'i
'to practice cannibalism'
b. kina 'eat two things together (starchy food and side dishes)'
c. kītaki 'eat starchy food or ripe bananas with coco'
d. 'ota 'eat raw things, Tahitian salad'
e. otai 'eat certain fruit (grated guava mixed with grated coconut)'
f. mafana 'drink the juice of the dish su before eating it'

So far we have focused on the core participants (Agent and Patient) for the description of cross-linguistic differentiation of lexical inventories. Let us now turn to the other parameters of variation. The Manner of eating is clearly expressed

5 This was pointed out to us by an anonymous reviewer. Note that if liquid food or medication is given to babies or elderly people one can also use boire 'drink' in French (boire le médicament à la cuillère, lit. 'drink the medicine with a spoon'). 
in verbs like wolf down, devour, slurp in English and chipoter 'pick/nibble at the food', picorer 'eat very little/selectively', dévorer 'devour, wolf down', engloutir 'wolf down' in French or schlingen 'wolf down', herunterwürgen 'gulp down' in German. More often than not these expressions seem to be based on Manners of eating observable in the behavior of animals. As mentioned above, in German the verbs used with animal subjects may also be used with human subjects to describe immoderate eating and drinking.

Instruments are rare lexical components of verbs of eating, and if they are lexicalized, they are often morphologically complex or the result of conversion. Examples that come to mind are aus-löffeln 'spoon out', auf-gabeln 'pick/dig up' in German, verbs that are primarily used in metaphorical extensions (e. g. aus-löffeln with the meaning 'face the music', auf-gabeln as 'accidentally pick up a person').

The Time of eating is expressed in such lexemes as déjeuner 'have breakfast', goûter 'have an afternoon snack', diner 'have dinner', souper 'have supper' in French, as zaftrakat' 'have breakfast', obedat' 'have lunch', uzhinat' 'have dinner', etc. in Russian, and as dine and sup in English. The Place of eating is rarely expressed, except for cases like piqueniquer 'eating outside' in French.

Some languages make lexical differentiations concerning the Result of eating, i. e. the effect either on the Patient (Germ. auf-essen 'eat up', aus-trinken 'drink up') or the Agent (sich voll-essen, sich satt-essen 'eat one's fill', sich über-essen 'overeat'). ${ }^{6}$ As these examples illustrate, the relevant verbs are typically morphologically complex and contain an independent morpheme indicating results.

Having pointed out some general parameters in the lexicalization patterns of eating verbs, we will now turn to a group of languages that exhibit particularly rich inventories of verbs of eating, i. e. selected Melanesian and Polynesian languages.

\subsection{More fine-grained distinctions in Melanesian and Polynesian languages}

Some of the parameters discussed in the preceding section can be illustrated with examples from East Futunan (cf. Moyse-Faurie 1993). In this language a generic verb (kai) corresponding to eat is available and is used both transitively and intransitively. This verb is often used with modifiers indicating, for instance, Manners and Results of eating. Consider the following examples:

\footnotetext{
6 Cf. Putnam \& Gast (2012) for a semantic analysis of 'excess predicates' like overeat.
} 

a. kai fakavale
'to overeat' (Result ${ }_{\mathrm{Ag}}$ )
b. kai mākona
'eat one's fill' (Result ${ }_{\mathrm{Ag}}$ )
c. kai okooko
'eat moderately' (Manner)
d. kai vasuvasu
'eat in accordance with what is customary'
(Manner)

The examples given so far suggest that East Futunan uses simple verbs for specific types of food (cf. (6) above) and complex constructions to indicate the Manner or Result of eating, but there is actually no complete complementarity between the generic verb kai and specialized verbs like those in (6). There are also cases of specialized verbs referring to the Manner of eating (cf. (8)) and we find kai with objects indicating the type of food (cf. (9)).
a. ma'ama'aga
'eat excessively' $\left(\right.$ Result $\left._{\mathrm{Ag}}\right)$
b. pakalamu
'chew well; eat noisily (of people)' (Manner)
'eat only fish and meat/proteins'
b. kai koko
'eat all kinds of things'
c. kai tauvalo
'eat constantly good things'

(9) a. kai samukō

If we broaden out our perspective from the case of East Futunan to Melanesian languages of New Caledonia and Polynesian languages in general, we get a more or less uniform general picture, in spite of some differences between New Caledonian Mainland languages (several specific terms), the languages of the Loyalty Islands (general eating term versus meat/fish distinction) and Polynesian languages (raw versus cooked, only one sort of food or different sorts). Before looking at the more fine-grained and, from the perspective of European languages, remarkable examples, let us briefly consider the higher-level eating terms that are available. As pointed out in Section 3.1, East Uvean has a (honorific) verb which is used for both eating and drinking (taumafa). A more or less general term for 'eat' (kai), which is used both intransitively ('have a meal') and transitively, is found in East Uvean and Tongan, in addition to East Futunan. On the Loyalty Islands there are terms used intransitively and for eating starch food, fruits, vegetables (but not for meat): kaka/kakan in Nengone, and xen in Drehu. The New Caledonian Mainland languages have a term for 'eat' which is used intransitively and for most fruits and salad (but not for bread, coconut, banana or meat), i. e. Xârâcùù da and Ajië ara.

We can use examples from East Uvean to illustrate some eating verbs relating to the Manner of food consumption. There is a verb for 'stuffing oneself', i. e. 
fa'apuku/ha'apuku. If food is swallowed without chewing (ripe bananas), or if an eater has no teeth, momi is used. Noisy eating habits, compared to those of animals, are implied by the verb pakalamu. Finally, there is a verb for enjoying food, i. e. 'unani.

More specialized verbs of eating are typically differentiated into those requiring starch food (yam, taro, sweet potato, rice, banana, manioc, bread) and those requiring meat, fish or related types of food (e. g. animal products). The first class is found in the New Caledonian Mainland languages Xârâcùù $(k e ̂)$ and Ajië (kâi). All New Caledonian languages have verbs that are used with meat, fish, coconut (perhaps as a metaphorical extension of flesh), as well as egg and milk products (Nengone ia/ian, Drehu öni, Xârâcùù xwè, Ajië oi). New Caledonian and Polynesian languages have verbs of eating that are restricted to the consumption of sugarcane, orange and all other fruits that are sucked (Xârâcùù xwii, Ajië wa, East Uvean/East Futunan/Tuvaluan gau). Polynesian languages have verbs for raw food (fish, meat, shells), i. e. 'ota (East Futunan, East Uvean) and ota (Tuvaluan), deriving from PPn *'ota.

While such degrees of specificity are surprising from the perspective of European languages, it is probably even more uncommon to find specific verbs which relate not to the type of food, but to the number of types of food consumed. In Polynesian languages there are verbs that are used when only one thing is eaten, i. e., either starch food or bread without any meat or fish, or vice versa. These verbs are also used for leftovers (non-protein food): hamu/hamuko (East Uvean), (kai) samukō (East Futunan), and samusamu (Tuvaluan), all deriving from PPn *hamu.

Finally, there are also verbs of eating that are used when both starch food and fish or meat is consumed. Xârâgurè haakéi/xaakéi means (roughly) 'eat as accompaniment to protein food', and the meanings 'food eaten with another food as relish' or 'meat or fish provided to eat with vegetable food, relish' are expressed by the verbs kinnaki (Māori), kīkì (East Uvean), kiki (Tuvaluan), and (kai)kina (East Uvean, West Uvean), all deriving from PPn *kina. Even more specifically, the verb $k i$ taki (East Futunan, East Uvean) denotes an event of eating both starch food and coconut flesh or ripe bananas.

Obviously, food can also be combined with beverages, and given the highly specific verb meanings mentioned above it is perhaps not surprising to see that there are also verbs for food-beverage combinations. The East Uvean verb omaki 
(< PPn *omaki) and the Tuvaluan verb peke mean 'dunk food into water before eating it'. East Uvean fono ( $<\mathrm{PPn}{ }^{*}$ fono) is used when food is eaten with kava.

We will conclude this overview of the rich inventories of verbs of eating found in Melanesian and Polynesian languages with examples of verbs that do not denote eating actions, but the desire to eat specific things, i. e. terms meaning 'feel like eating specific kinds of food'. East Futunan $g \bar{a}$ and Haméa treu mean 'crave for proteins (i. e. fish or meat)', and East Uvean as well as Tongan 'umisi (< ProtoFijian *kusima) means 'crave for fish/seafood'.

\subsection{Towards cross-linguistic generalizations}

Obviously, it is very difficult to make generalizations in lexical typology in general, and even more so in the (highly) abstract domain of verbal meanings. We will propose hierarchies which rank properties of event descriptions in terms of the (hypothesized) likelihood that these properties will be lexicalized in specific verbs. The hierarchies will rank pairs of parameters that make similar contributions to the predication in question. Before formulating such hierarchies, we will consider the various parameters individually, however.

In the languages that we have looked at, the most important property that is lexicalized in eating verbs seems to be the type of food or beverage consumed (the Patient). In Europe (as well as probably in most other parts of the world), there are consistent differentiations between eating and drinking, and languages that do not make a distinction here at all seem to be rare. As the Melanesian and Polynesian languages discussed in Section 3.2 have shown, there are hardly any limits on the level of specificity found in differentiations according to the type of food consumed.

The Agent has been found to be relevant in German. We have not investigated whether there are distinctions according to age, but it seems likely to us that cross-linguistic studies will reveal that at least some languages use specific eating verbs for children. Still, distinctions according to properties of the Agent are clearly less prominent than distinctions according to properties of the Patient, in terms of both the number of languages which make such distinctions, and the number of distinctions made in the languages that do (basically, human vs. non-human).

A property of eating verbs that has been found to be relatively prominent concerns the Manner of consumption. Note that this parameter is obviously not totally independent of the type of food consumed or of selectional restrictions 
on the Agent. It makes a difference who eats what. As has been pointed out, in many cases it is probably difficult to tell apart whether it is primarily the Manner of eating or the type of food that is lexicalized in a given case. Soups are liquid but they are 'eaten' in English, perhaps because they are consumed with a spoon and with specific portion sizes. As was pointed out in Section 3.1, Japanese treats soups in the same way as beverages and thus seems to distinguish more clearly on the basis of substance rather than the Manner of eating; but then, medicine (including pills and powders) patterns with beverages, suggesting that it is the absence of chewing which characterizes actions denoted by taberu/tabemasu.

The Instrument of eating, by contrast, seems to be less commonly encoded, and we have noticed that the relevant verbs are often interpreted metaphorically in German. Few lexical distinctions have also been found with respect to the Result of eating or drinking events. The examples that we have considered were all Agent-related, e.g. overeat. Such predicates typically appear to be morphologically complex.

Verbs of eating which lexicalize the Time of eating are widespread in Europe, perhaps because different types of meals are consumed at specific times of the day (cf. Section 5 on explanations). A verb like Germ. frühstücken 'have breakfast' is thus quite informative, as it conveys information not only about the Time of eating but also about the food that is typically consumed. In Polynesian and Melanesian communities the same type of food is eaten at all times of the day and this could be the reason that Oceanic languages do not have differentiations of this kind. The Place of eating, by contrast, is hardly ever lexicalized, and given that there is not much variation possible, it is not surprising to find that this parameter is of minor importance in the present context.

On the basis of the considerations made above, we propose the following hierarchies of properties associated with eating and drinking events:

(10) Hierarchies for eating and drinking verbs
a. Patient $>$ Agent
b. Manner > Instrument
c. Time $>$ Place

Given that the relationship between Manner and Result has played an important role in recent discussion of lexical semantics, we will also consider the relationship between these two properties. Their lexical encoding seems to be largely complementary. Our data thus lends support to the Manner/Result complemen- 
tarity hypothesis. In eating verbs, the encoding of Manner is clearly more prominent than the Result, abstracting away from the category-level entailment that food is consumed. We can thus postulate the hierarchy in (11).

(11) Manner and Result in verbs of eating and drinking Manner > Result

The hierarchies in (10) and (11) are, obviously, intended as hypotheses about the tendencies for specific properties of events to be lexicalized in the world's languages. Such hierarchies can of course only be probabilistic, as they are certainly, at least partially, culture-specific. Those properties located to the left are (hypothesized to be) more likely to be lexicalized in verbs of eating or drinking than those further on the right.

\section{Verbs of physical impact}

We will now turn to an entirely different group of verbs, which call for different generalizations and explanations, i. e. verbs of physical impact. We have chosen the three groups 'verbs of killing', 'verbs of beating' and 'verbs of cutting' because the relevant verbs seemed to exhibit interesting differentiations in the languages investigated by us. Needless to say, there are certainly many more interesting verbs belonging to this group, and the discussion in this section is far from exhaustive.

\subsection{Verbs of killing}

The concept of 'killing' is expressed by prototypical transitive verbs like Engl. kill, Germ. töten, Fr. tuer, etc. (cf. Beavers \& Koontz-Garboden 2012 for a recent study of killing verbs). Taking again the selection of Agents as a point of departure, we can see that in many European languages there is a neutral verb, such as the three verbs mentioned above, that can be used irrespective of the exact nature of the Agent, i. e., for human and non-human Agents alike. Moreover, there are verbs of killing that require premeditation and, hence, a human Agent (e. g. assassinate, murder), and certain verbs like shoot require a human Agent for non-linguistic reasons, as shooting implies an intentional Agent with certain fine motor skills (and it is questionable if we would use the verb erschießen 'shoot dead' if an animal - say, a cat - accidentally shot a person by playing with a gun). In more specialized registers, there are also verbs that are used specifically for animals, e. g. German reißen (of lions, tigers, wolfs, etc.) and schlagen (of predator birds). 
If we consider the selectional restrictions concerning the Patient, we find, again, some interesting cases of differentiation, like Engl. slaughter or Germ. schlachten, Fr. abattre, etc., which are used for killing animals (for food production), and this seems to be the only restriction found in that domain, unsurprisingly so, since only animals and human beings can be killed. ${ }^{7}$

An interesting and subtle difference in the lexical inventories of English and German, however, is described by Plank (1984). There are as many as five possible translations for the English verb shoot in German, depending on the Patient and the Motivation of the activity. The (intransitive) German root schieß 3 -is similar to Engl. (transitive or intransitive) shoot insofar as it does not carry any resultative implications. This root is also used transitively in a highly specialized meaning, however, i. e. when referring to the shooting of game animals (cf. 12a). In most cases, the root schieß $\beta$ - is used transitively only with some resultative prefix of the type illustrated in (12b) to (12e).

(12) a. schießen

Karl hat in der letzten Jagdsaison 10 Wildscheine geschossen.

'Charles shot 5 wild boars during the last hunting season.'

b. ab-schießen

Fäger sollen noch mehr Wild abschießen.

'Hunters are urged to shoot more game.'

c. er-schießen

Die Terroristen haben vier Zivilisten erschossen.

'The terrorists shot 4 ordinary civilians.'

d. tot-schießen

Wir mussten den entlaufenen Löwen totschießen.

'We had to shoot the escaped lion.'

e. nieder-schießen

Der Polizist wurde auf offener Straße niedergeschossen.

'The police man was shot in the street.'

$A b$-schießen focuses on 'successful completion' - typically used with flying objects like birds (and also airplanes) - and does not convey any specific Motivation - unlike (transitive) schießen, which is clearly associated with hunting, and thus either the reduction of game population or the supply of meat. Er-schießen is

7 Of course there are metaphorical extensions, such as to kill time, Fr. tuer le temps, Germ. die Zeit totschlagen. 
only used with human objects and perhaps higher animals. Tot-schießen, which carries a connotation of child language, could be used if danger is to be avoided, or if a person or an animal is killed ad hoc, i. e. if there is no specific Motivation. Nieder-schießen, finally, which is restricted to human Patients, is not a verb of killing, and the survival of the object would even be assumed by implicature. The English verb shoot is completely neutral with regard to all these facets of meaning.

Let us consider the parameter of Motivation in more detail. For the killing of persons, three major Motivations can be distinguished: persons may be killed for criminal reasons (e.g. murder), for political or ideological reasons (e. g. assassinate), and they may be killed 'legally' (e.g. execute). Note that the two cognate verbs assassiner in French and assassinate in English have different implications with respect to both the Patient and the Motivation of a killing event. While the former permits any kind of human object, the latter is restricted to public figures.

Given that killing is an ethically highly sensitive action, it is not surprising to find that languages indicate why someone is killed. This distinguishes verbs of killing from verbs of eating. As we will see below, the Motivation is also rarely encoded in verbs of beating or cutting (cf. also Section 5 on explanations).

The examples in (12) above also illustrate a further parameter of variation, i. e. the Instrument of killing. The English verb shoot and the stem appearing in all its German counterparts, viz. schießen, denote actions in which a rifle, gun or pistol is used. Consider now the examples given in (13) (from German and French) as well as their English translations. These verbs imply the use of some specific Instrument:
a. er-stechen 'stab' ('killing with a knife', Fr. poignarder)
b. er-würgen 'strangle' ('killing with the hands', Fr. étrangler)
a. er-schlagen
'slay' ('kill with a club/blunt object', Fr. assommer)
b. er-schießen
'shoot dead' ('kill with a gun', Fr. fusiller)

In the case of killing verbs, it is sometimes difficult to tell whether it is an Instrument or a Manner that is encoded. More broadly speaking, we could also use the term 'method'. Levin (1993) distinguishes between 'murder verbs' - which imply no specific Manner (or method) (cf. (15)), and 'poison verbs', which do provide a Manner, but which do not entail the death of the Patient (cf. (16)).

(15) Levin's (1993) murder verbs

assassinate, butcher, dispatch,

eliminate, execute, immolate, kill, liquidate, massacre, murder, slaughter, slay 
(16) Levin's (1993) poison verbs

asphyxiate, crucify, drown, electrocute, garrotte, hang, knife, poison, shoot, smother, stab, strangle, suffocate

Beavers \& Koontz-Garboden (2012) have argued for distinguishing a third class, i. e. 'manner-of-killing verbs' (cf.(17)). Some of these verbs are categorized as poison verbs by Levin (1993).

(17) Beavers and Koontz-Garboden's (2012) manner-of-killing verbs crucify, drown, electrocute, guillotine, hang

We will return to the (controversial) question of whether verbs like those in (16) encode Manner and Result (death) at the same time below. For the time being, let us consider some German and French verbs of killing which do appear to encode both a manner of killing and the Patient's death in (18). Note that most of these verbs are not morphologically simple - the German verbs carry a resultative prefix - and therefore do not represent a challenge to the claim of Manner/Result complementarity made by Levin \& Rappaport Hovav (2006).
a. er-tränken 'killing by putting someone under water', (Fr. noyer)
b. ver-giften 'poison' 'killing with poison', (Fr. empoisonner)
c. ver-brennen 'burn' 'killing by fire', (Fr. brûler)
d. er-hängen 'hang', (Fr. pendre)

Note that German also has a couple of non-prefixed stems describing the Manner of killing, though it uses the suffix -ig in some cases to form denominal verbs:
a. köpf-en
'behead', (Fr. décapiter)
b. stein-ig-en 'stone to death', (Fr. lapider)
c. kreuz-ig-en 'crucify', (Fr. crucifier)

Systematic inventories of verbs of killing providing information about the Instrument used are found in Melanesian languages of New Caledonia. In Xârâcùù, for example, verbs translating the action 'to kill' are compounds which are made up of an element indicating the Manner or Instrument, and a second element indicating the Result (cf. Moyse-Faurie \& Néchérö-Jorédié 1986, Moyse-Faurie 1995). The first component is often a bound form (with CV-syllable structure) derived from a verb through a reduction of all but the first syllable (Ozanne-Rivierre \& Rivierre 2004). The second, recurrent component-amè/-èmè/-ömè 'completely, 
definitive, lethal' could be identified with the stative verbs amè 'to be paralyzed', or perhaps - $m \dot{e}$ 'to be extinguished', and thus provides the resultative component. Here are some examples:
a. bo-èmè
bo
b. cha-amè cha
c. chuu-amè chuu
d. fì-èmè $f \hat{\imath}-<f \hat{l} d a$
e. kwi-amè $k w i-$
f. $p w \hat{a}-\hat{a} m \dot{e}$ $p w a \hat{a}^{-}$ 'kill by hitting with a stick'
'hit with a stick or a bludgeon' 'kill s.o. with an axe'
'cut with an axe or a saber' 'kill with a fist' 'hit, pound (with a downward motion, with fist)' 'kill with a stick' 'hit with an instrument' 'kill with a downward movement' 'kill with an instrument and a downward movement'
g. sö-amè ( söömè) sö
'kill, beat unconscious with a stick' 'action of throwing a war club'
h. ta-amè ta
i. tè-èmè tè-
'kill, beat unconscious with your hand'
'hit, make a circular movement with your hands' 'kill with gun, arrow' 'shoot, throw a long object' 'kill with hands, or with a long object' 'action with hands'

The most remarkable fact is perhaps that there is no cover term for all these verbs, i. e. no hyperonym that is unmarked for the Manner of killing (though a euphemism may be used, i. e. sa 'hit'; see also Section 4.2).

A comparison of the specific (related) pairs of parameters that may be encoded lexically, as provided in the discussion of verbs of eating and drinking in Section 3 , is more difficult to carry out in the case of killing verbs. Note first that, again, the Patient seems to be more prominently encoded than the Agent. For Agents, we basically have a binary distinction between verbs restricted to human Agents (murder) and generic verbs (kill). Moreover, we have seen that there are many ways of encoding an Instrument or Manner of killing, even though such verbs are often morphologically complex or derived via conversion. Given that it is often difficult to determine whether it is primarily a Manner or an Instrument that is encoded, we have not differentiated between these aspects of meaning. 
Results beyond the category-level implication of death - verb-specific Results concerning either the Agent or the Patient - do not seem to figure prominently in the class of killing verbs. By contrast, the Motivation has been shown to be an important parameter, at least in the European languages that we have looked at. Assuming that Instrument and Manner are ranked more or less equally, we can thus postulate the following hierarchies:
a. Patient $>$ Agent
b. Instrument $\sim$ Manner
c. Motivation $>$ Result

Considering the encoding of Manner and Result, it is clear that Manner is more prominent, at least if we focus on verb-specific Results. Agent-related Results do not seem to be encoded at all. We have not found a single verb of the type The soldier overkilled, in the sense of 'he killed too many persons and therefore felt bad'. Patient-related Results appear more likely, but verbs like Germ. zer-stückeln 'hack to pieces' should probably not be categorized as verbs of killing, as one can also hack a computer to pieces. Accordingly, we propose the following hierarchy:

(22) Manner and Result in verbs of killing

Manner > Result

On the basis of these comparative observations we can now return to the recent controversies concerning specific groups of verbs as counterexamples to the hypothesis on Manner/Result complementarity. In two recent papers, Beavers \& Koontz-Garboden (2012) and Husband (2011) have argued that counterexamples can be found in three groups of English verbs: (a) in verbs of ballistic motion (fling, flip, toss, kick, flip), which express displacement and manner of motion, (b) in verbs of cooking (sauté, poach, braise) and (c) in some verbs of killing, the only case that will be discussed here. It is argued in these studies that verbs like those in (17) (crucify, drown, hang, guillotine, electrocute) entail both a Manner and a Result (death), thus taking issue with Levin \& Rappaport Hovav's complementarity hypothesis. ${ }^{8}$ Both the complementarity hypothesis and its critical discussion throw some interesting light on our comparison. Note first of all that our data from German (as well as other Germanic languages) and Xârâcùù confirm the complementarity hypothesis. Whenever both a Manner and the Result of the violent action are encoded in a verb, the verb is bi-morphemic encoding these two

8 Other possible counterexamples are perhaps provided by slay 'kill in a violent way' and slaughter 'kill large numbers in a way that is cruel and unnecessary'. 
components in separate parts. In German the verbal root encodes Manner and an inseparable prefix (er-, ver-, zer-) the result (death), in contrast to English, where a corresponding form with a prefix is not available and where complex tests are required to determine whether a result is entailed in addition to the manner encoded by a root:

$\begin{array}{ll}\text { German } & \text { English } \\ \text { a. stechen - er-stechen } & \text { 'stab' } \\ \text { b. schießen - er-schießen } & \text { 'shoot' } \\ \text { c. würgen - er-würgen } & \text { 'strangle' } \\ \text { d. schlagen - er-schlagen } & \text { 'slay' }\end{array}$

This contrast between English and German ties up nicely with the fact that German has almost no simple roots expressing Direction of motion, whereas English may encode both Manner and Direction in simple roots. The complementarity hypothesis is thus confirmed for some Germanic and some Oceanic languages. Moreover, there is another problem that needs to be solved in any attempt at validating or attacking the complementarity hypothesis: The problematic cases are largely denominal verbs borrowed from other languages (guillotine, crucify, electrocute) in one list and/or morphologically complex (be-head, de-capitate) in the other. In other cases, it is not clear whether a verb does or does not entail the death of the Patient. The fourth stanza of Friedrich Nietzsche's poem Unter Feinden ('Among enemies') opposes 'hanging' to 'dying' (there is obviously some 'poetic license' involved):

(24) Auch nach hundert Todesgängen

bin ich Atem, Dunst und Licht.

Unnütz, unnütz, mich zu hängen!

Sterben? Sterben kann ich nicht!
Even after a hundred walks to deaths

I am breath, mist and light.

Useless, useless, hanging me!

Die? Die, I cannot.

Our tentative conclusion of the preceding discussion is (a) that generalizations across lexicons about possible and impossible word meanings should be based on broad samples of languages, and (b) that it would not be completely surprising if some generalizations have to be relativized to certain historical layers of the vocabulary. Moreover it is hard to separate purely lexical entailments from matters of world knowledge, as shown by the example from Nietzsche's poem. 


\subsection{Verbs of beating}

Our next semantic domain and the relevant subsets of basic vocabulary also have to do with more or less unfriendly interactions between man and his fellow human beings or with his environment. The cover term 'verbs of beating' subsumes verbs which denote actions in which force is exerted manually, with fast movements on another object, typically with a body part or blunt Instrument. It is probably not surprising that the aspects of meaning that we find encoded in the relevant verbs are similar - though not identical - to those that we found in the domain of killing. Again we will use English, German and French as starting points and turn to Oceanic languages for examples of more extensive differentiations.

The domain of 'verbs of beating' includes at least the following expressions in English: hit, beat as the most general expressions; crash, smash, trash, smite, slay, knock, which incorporate an element of great force and characterize the Result as devastating; kick (foot), punch (hand), slap (hand), smack (hand), cane, whip, flog, lash, flail, which incorporate a reference to the Instrument of the action. The last five of these are de-nominal verbs indicating the Instrument explicitly and are typically found in contexts of punishment.

In German we also have de-nominal verbs expressing the Instrument directly (prügeln 'beat with a club', 9 aus-peitschen 'whip'), but such lexical differentiation as we find is mainly based on formal modifications of the basic general verbs schlagen and hauen through separable and inseparable prefixes, the most common strategy of lexical differentiation in typical Germanic languages. Many of these formations (an-schlagen 'strike against, post', ab-schlagen 'knock off, deny', vorschlagen 'propose', auf-schlagen 'knock open, serve [in tennis], pitch [a tent]', unter-schlagen 'embezzle', über-schlagen 'flip over, estimate', um-schlagen 'knock over, transact', etc.) are nowadays mainly restricted to metaphorical or idiomatic usage. The set of semantic aspects expressed by the verbs that are normally

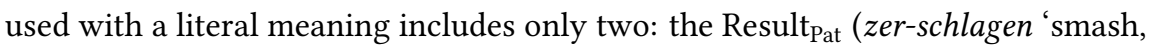
disintegrate', er-schlagen 'slay', be-schlagen 'stud', zusammen-schlagen 'beat up', $a b$-schlagen 'knock off'), and the Direction of the hitting action (ein-schlagen 'inbeat/bang in', aus-schlagen 'out-beat/knock out', zu-schlagen 'to-beat/strike', anschlagen 'on-beat/butt'). The two parameters are hard to keep apart, however, as the Direction of a hitting action - for instance, ein- 'in(to)', aus- 'out' - has

9 The verb prügeln, while being a derivate of the noun Prügel historically speaking, is also used generically today, i. e., as a common verb of beating. It implies a high degree of force, however. 
primarily implications on the Result Pat , e.g. insofar as hitting 'into' a window implies that the window breaks. Ein Fenster einschlagen thus means 'break a window', and einen Zahn ausschlagen implies that a tooth was lost. The originally directional prefixes have thus assumed basically aspectual functions and German

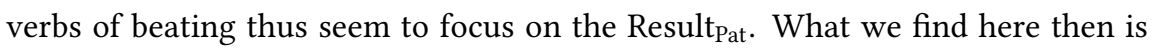
a further confirmation of the generalization stated in Beavers et al. (2010).

In French, frapper, taper, battre are the more general terms for actions of beating, but there are also several specific terms, such as gifler 'slap' (with hand, in the face) or claquer 'beat lightly (with hand)', cogner 'punch', 'bang', 'knock' (hit with fist or instrument in fist), fouetter 'whip', rosser 'thrash (beat in a violent manner)'.

Turning to Melanesian languages, we find that in Xârâcùù, the relevant subset of the vocabulary manifests a higher degree of differentiation than in the two European languages just discussed. As far as the formal expression is concerned, we find an interesting similarity with processes of derivation in Germanic. The verbs to be discussed are compounds where the first element is a prefix derived from a verb of exercising force by reducing all but the first syllable. In addition to the basic general verb sa 'hit, beat', there is a wide variety of verbs exhibiting this basic structure, all expressing variations in the semantic domain of hitting and beating. Interestingly enough, all of these verbs express the semantic dimension of Instrument in addition to the fact of hitting or beating and the Result of this activity. The examples in (25) are based on the verb dì- 'hit with the fist, punch':
a. dì-kari 'punch gently'
b. dì-kè 'box, punch'
c. dù-chëe 'fail to hit with a punch'

In (26), some examples are provided of verbs based on the root $f^{i}$ - 'hit with an Instrument' $(<f i d a)$. Some of these examples provide information about the Instrument and/or the Result.
a. $f \hat{\imath}-a k \grave{e}$
'hammer in' (Instrument)
b. fî-atapö
'hitting on sth. to explode it' (Result)
c. fì-buru
'break s.th. by hitting' (Result)
d. fì̀èmè
'kill by hitting with a stick' (Instrument, Result)
e. $f \hat{\imath}-w i$
'hit on s.th. so that it falls' (Result)

Finally, a number of verbs can be derived from the roots sö- 'hit with a circular movement of the hand or arm'. There is, thus, a Manner component encoded in 
all these verbs. In addition, there are often aspects of Result expressed, and some verbs are used for specific types of Patients:
a. sö-chèpwîr̂̂̀ 'turn over by hitting' (Result)
b. sö-chö 'bend sth. by hitting with hand' (Result)
c. sö-kai
'wipe out with hand (a mosquito)' (Patient, Result)
d. sö-paari 'remove weeds' (Patient, Result)
e. sö-pisii 'wipe away' (Result)

A major difference to the verbs of killing seems to be that the Motivations for an action of beating do not seem to be encoded in verbs of beating. Using the same pairs of parameters that we compared for verbs of eating and drinking and verbs of killing, we can thus postulate the following hierarchies:
a. Patient $>$ Agent
b. Instrument $>$ Manner
c. Result $>$ Motivation

The Patient is, again, more prominently encoded than the Agent. Unlike in the case of verbs of killing, it seems to us that on the whole, the Instrument is more prominent in verbs of beating than the Manner. Another difference to verbs of killing is that languages seem to put more emphasis on the Result than on the Motivation of beating.

As far as the relation between Manner and Result is concerned, their exact interaction is hard to determine. As has already been pointed out, verbs like crash, smash, trash, etc. imply a certain degree of force - which could be regarded as an aspect of Manner - and it is unlikely that an object will remain undamaged if it is smashed, for instance, so some Result seems to be implied as well (cf. the denial-of-result test applied by Beavers \& Koontz-Garboden 2012: $336 \mathrm{ff}$.). Some of the verbs discussed in this section are thus potential counterexamples to the Manner/Result complementarity hypothesis. However, it seems to us that - in monomorphemic words at least - both Manner and Result are only sparingly encoded, insofar as the only prominent Manner specification that we have found is that of 'force', and implications concerning the Result hardly go beyond attributing a high degree to the (category-level) entailment of 'damage' done to the Patient. 


\subsection{Verbs of cutting}

The action of cutting, i. e., of using a of sharp Instrument to change the physical integrity of an object or, to use Levin \& Rappaport Hovav's (2013:5) words, "the production of an incision with clean edges", is just as dramatic an act of interference into the existence and shape of living organisms or objects as the actions discussed before, but in contrast to the preceding two domains this action is typically associated with creative activities such as preparing food, constructing, repairing s.th., etc. (for a comparative study, cf. the special issue of Cognitive Linguistics edited by Majid \& Bowerman 2007, in particular Majid et al. 2007). If we look at our three European languages again which provide the starting point for our investigation, we note that there is not much differentiation in the basic vocabulary of English. In addition to the most general and most versatile verb cut, and its combinations with particles (across, off, out, up, through, lengthwise) there are verbs like chop, clip, prune, hew, carve, trim, slit, slice, nearly all of them incorporating some characterization of the Result ${ }_{\text {Pat }}$ of the action, as well as a few very specialized 'synonyms' such as mow (grass) and amputate (leg or arm) exhibiting specific collocational distinctions. Examples of more specific verb meanings are provided by the verb hew, which typically implies an axe as Instrument and stone or wood as Patients, and the verb slice, which exclusively expresses the Result of an action.

In French the major distinctions in the corresponding basic vocabulary are the ones between couper 'cut', hacher 'chop', fendre 'split', émonder 'prune', tailler 'cut, prune' and découper 'cut up, carve'. The first verb is the most general and versatile one and implies neither the use of specific Instruments, nor any specific Results. Découper, by contrast, is associated with a specific purpose or goal (i. e., Motivation) and expresses the process of cutting according to a specific plan (découper une étoffe, du carton 'cut up the fabric, cardboard') in order to create something. Découper un article means to rearrange the sections of the article, couper un article means to cut or drop the article. In the remaining verbs the Result is lexicalized: fendre 'separate, create two parts', tailler 'cut with a specific shape in mind', hacher 'cut into small pieces', émonder 'prune (a tree)'.

In German, differentiation between certain subtypes of the general action is, again, achieved through the use of separable or inseparable prefixes. The resultant distinctions mostly relate to the Result of an action (be-schneiden 'clip', zer-schneiden 'cut (into pieces)', ab-schneiden 'cut off', an-schneiden 'cut (a cake)', 
auf-schneiden 'cut open', aus-schneiden 'cut out'). The verb most closely corresponding to découper in French is zuschneiden.

In Oceanic languages we find a wide variety of verbs of cutting whose choice depends primarily on the Instrument (including body parts) used, on the Result and the Manner of the action, as well as on the Patient of the activity. The following list is a first attempt to systematize the factors relevant for the choice of a verb.

\section{(i) Choice depends primarily on the Instrument and the Result}

In Xârâcùù (New Caledonia), the first part of the verbal compound indicates the Instrument or the body part involved in the cutting event. The following expressions are examples of such first parts: $k i^{-}<k i r i$ 'saw', $k w i^{-}$'cut with a tool in the hand, from top to bottom', $p w \hat{a}$ - cut or split with a warclub', cha 'cut with an axe or a saber held in the fist'. The second part of a compound typically refers to the Result of the cutting. The examples in (29) - (33) provide illustration for this Instrument+Result-pattern:

(29) Xârâcùù

cha- 'cut with an axe or a saber held in the fist'
a. cha-cöö 'cut the bark vertically' (cöö 'break into fibers')
b. cha-chëe 'miss a cut, cut across' (-chëe 'miss')
c. cha-gwéré 'succeed in cutting with an axe' (-gwéré 'succeed')
d. cha-körö 'cut into pieces' (-körö/-görö 'break into pieces')

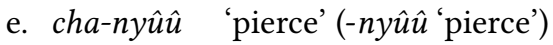
f. cha-pèrè 'cut efficiently' (-pèrèl-bèrè 'efficiently')
g. cha-pöru 'cut the bark from every part of the stem' (pöru/-böru 'peel')
h. cha-puru 'cut in two' (-puru/-buru 'cut in two vertically')

(30) $k i-<k i r i \quad$ 'saw'

ki-caa 'saw away the slit of wood' (-caa 'move away')

(31) $k w i^{-} \quad$ 'cut with a tool in the hand, from top to bottom'

kwi-puru 'cut in two with a tool' (-puru/-buru 'cut in two vertically')

(32) pwâ- 'cut or split with a warclub'

pwâ-dia 'split with a warclub' (tia/-dia, 'split')

(33) sö- 'make a circular movement with the hand or arm'

sö-puru 'cut in two with the hand' (-puru/-buru 'cut in two vertically') 


\section{(ii) Choice depends primarily on the Patient}

In the following (monomorphemic) examples from East Futunan the choice of the verb depends primarily on the Patient, i.e. on the material to be cut (e.g. hair, grass, wood, etc.):

(34) East Futunan
a. moli' $i \quad$ 'cut off a small piece of something'
b. mutusi 'amputate, cut off the tail of a pig'
c. paki 'cut off leaves or bananas'
d. $t \bar{a}$ 'i 'cut off, harvest (bananas)'

The verbs in (35) encode some additional aspect of meaning together with the Patient, e. g. the Instrument, the Result, the Place and the Motivation:

(35) East Futunan
a. autalu 'to cut the weeds with a knife, to weed' (Patient, Instrument)
b. fakainati 'to cut meat into portions' (inati 'parts, portions of meat') (Patient, Result)
c. fakasāfuni 'cut and adorn the hair of the bride' (Patient, Manner)
d. kati'i 'cut (sugar cane, coconut) with teeth' (Patient, Instrument)
e. koto 'cut off leaves (of the taro) from their stem by hand' (Patient, Instrument/Manner)
f. lovao 'cut plants alongside roads' (Patient, Place)
g. $t \bar{a} \quad$ 'cut wood for construction' (Patient, Motivation)

\section{(iii) Choice depends primarily on the Result}

The Result of cutting is encoded by some prefixes of Xârâcùù like, for instance, $j i-$, which combines with other predicates yielding rather specific meanings (cf. (36)). There are also monomorphemic words lexicalizing the Result of an action (cf. (37a)) and the reduplicated form in (37b)).

(36) ji- 'shorten, cut to a specific shape'
a. ji-kai 'cut up'
b. ji-kakai 'cut up in pieces'(-kai 'reduce to crumbs')
c. ji-mîldö 'sharpen' (mî̀ldö 'pointed') 
d. ji-pöru 'cut off bark, skin, to peel'

e. ji-puru 'slice', 'cut in two'

f. ji-tia 'cut lengthwise'
a. sërù 'cut into small pieces'
b. sësërù 'cut into very small pieces' (reduplicated)

Once again these examples seem to confirm the Manner/Result comlementarity hypothesis. Whenever both Manner and Result components are encoded in a verb, they are expressed by different parts of a polymorphemic verb. As the examples given above show, languages may vary considerably in the extent to which they lexicalize parameters of variation in the domain of cutting verbs. The European languages that we have looked at have rather poor vocabularies in the domain of cutting verbs and basically distinguish between different Results achieved by a cutting action. Other distinctions, in particular distinctions relating to the nature of the Agent, the Patient or the Instrument, are rare. The Manner of cutting is of course closely related to the Result, but otherwise not prominently encoded in verbal meanings.

A completely different picture emerges when we look at Oceanic languages. As has been demonstrated with examples from Xârâcùù, these languages make numerous and highly specific distinctions according to the parameters Patient, Instrument and Result, and the Manner of cutting is also often implied or even explicitly expressed. Even though this diversity renders any generalization in the domain of cutting verbs difficult, we will, again, rank the pairs of dimensions that we also used for the other types of verbs.

First, it is obvious that the Patient plays a more prominent role than the Agent. With respect to the relation between Instrument and Manner, we can note that there seems to be hardly any difference between the two parameters in the languages investigated by us. European languages care little about either of them, and the Oceanic languages that we have considered make distinctions according to both parameters. In lack of further comparative evidence, we will therefore assume that both parameters are ranked equally. The Result, finally, is clearly a very prominent aspect of meaning and is certainly more important than the Motivation of an action, since manipulation of and interference with the integrity of an object is usually goal-directed. The hierarchies characterizing the domain of cutting verbs can thus be represented as in (38):

a. Patient $>$ Agent 
b. Instrument $\sim$ Manner

c. Result > Motivation

As has been mentioned, these hierarchies are basically identical to those characterizing verbs of beating, with the exception that there does not seem to be any noticeable difference between Instrument and Manner in the class of cutting verbs.

Comparing the Manner and the Result of a cutting action, it is probably not surprising to find that the (Patient-related) Result is more important than the Manner of cutting. There are not so many manners available in which an object can be cut. We will thus assume that Manner and Result are ranked as shown in (39). Interestingly, there seem to be hardly any examples that combine the encoding of Manner with that of Result, which seems to lend support to Levin \& Rappaport Hovav's claim of Manner/Result complementarity.

(39) Manner and Result in verbs of cutting

Result > Manner

\subsection{Some generalizations}

We have been rather cautious in formulating our generalizations and have only opposed pairs of parameters to each other which make a similar contribution to the predication - Agent vs. Patient, Instrument vs. Manner, Motivation vs. Result. One generalization that emerged from all verb classes - quite unsurprisingly - is that the Patient is encoded more prominently than the Agent. The following hierarchy can thus be assumed to be more or less universal (cf. also Kratzer 1996, among others, on the different statuses of Agents and Patients in predications):

(40) Patient $>$ Agent

Distinctions according to the Patient have been found in all classes of verbs under consideration, and given that the nature of the Patient has a considerable impact on the type of event that is encoded, this is not surprising. We can make the following generalization:

(41) The Patient-Prominence generalization

Restrictions on, or implications about, the nature of the Patient are more commonly lexicalized than restrictions on, or implications about, the Agent. 
If we move on to the more 'peripheral' parameters of variation, we notice that Instrument and Manner are more prominently encoded than Time and Place. This is, again, not unexpected, as the Time and Place at which an event takes place are (genuinely) extrinsic, while the Manner and Instrument have a stronger impact on the lexical predicate. It is likely that Time and Place will only be encoded in verbs denoting activities that are habitually carried out by a considerable number of individuals in a speech community. Eating is such an activity, and we have pointed out that there are in fact lexical distinctions according to the Place and Time of eating in European languages.

Making an internal differentiation between the Instrument and the Manner of an event is tricky, as the two aspects of interpretation often overlap - the use of different Instruments implies differences in the Manner in which an action is carried out. The difference is that an Instrument is a 'genuine' participant of an event, while a Manner is a property of (some aspect of) the event in question. It thus basically subsumes all those properties of events which are not related to the use of a specific Instrument, e. g. the type of movement made (e.g. straight vs. circular, upward vs. downward, cf. the Xârâcùù examples in (19)), the 'speed' of movement, etc. We have proposed the following hierarchies for the classes of verbs investigated by us:
a. verbs of eating/drinking
Manner > Instrument
b. verbs of killing and cutting
Instrument $\sim$ Manner
c. verb of beating
Instrument > Manner

While all of the activities have in common that they imply the use of some Instrument, they differ in their internal event structures. Eating and drinking are complex events, with specific sub-events, e. g. biting, chewing and swallowing in the case of eating. Beating events, by contrast, are basically punctual and 'monolithic', i. e., they do not comprise sub-events but are typically carried out with a single movement (with the arm). Killing events are also basically punctual, or are at least conceived as such - as a matter of fact, intrinsically so, because by their very nature they focus on the endpoint of the action. Cutting events are located in between eating events and beating events with respect to the internal complexity 
of their event structure. For example, cutting often implies repeated movements in opposite directions and can thus also been broken down into sub-events.

The generalization that emerges from the considerations made above is the following:

(43) The MANNER-MOdification GENERALization

The Manner of an event is lexicalized more commonly in verbs denoting internally complex events, i. e., events comprising clearly distinguishable sub-events.

Let us now turn to the parameters Motivation and Result. These parameters are considered together because they correspond to the initial and the final stage of an event, respectively. We have found the following hierarchies:
a. verbs of eating, beating, cutting
Result > Motivation
b. verbs of killing
Motivation $>$ Result

As has been mentioned, verbs of killing carry category-level implications about the Result, i. e., the Patient is dead after the event has taken place. Differentiations with respect to the 'physical appearance' of the Patient are conceivable, but not prominently encoded in the languages that we have looked at. The Motivation of a killing event, by contrast, is an important factor. This is different in the other verb classes considered in the present study. Verbs of eating, beating and cutting focus more on the Result of the action than on the Motivation, which is hardly encoded at all. The difference seems to be that killing is an action which, by its very nature, can be assumed to carry ethical implications. One cannot kill just like that, and any killing event needs to be motivated in some way. This is obviously different for eating and cutting, though beating, too, may require some ethical justification at times.

What we can conclude from the preceding discussion is that - varying a famous quotation from historical linguistics ${ }^{10}$ - we can make the following generalization:

(45) The RELEVANCE-LEXICALIZATION PRINCIPLE

Languages lexicalize best what matters most to speakers.

10 "[G]rammars code best what speakers do most" (Du Bois 1985: 363). 


\section{Towards explanations}

We have discussed some dimensions of variation along which specific verb classes differ, and we have made some generalizations on the basis of examples from a small sample of languages. We will now consider possible explanations for the patterns and limits of variation that can be observed in the domain of event descriptions under discussion. The generalizations made in the preceding section lend themselves to three types of explanations. First, we can assume that there is a general tendency for verbs to encode 'more intrinsic' properties to a greater extent than 'more extrinsic' ones. In other words, the stronger the impact of a parameter on the internal make-up of a given event, the more likely the relevant parameter will be encoded lexically. This principle accounts for the fact that Patients are more prone to be encoded lexically than Agents, and that Instruments and Manner specifications are more likely to be encoded than Time and Place. The explanatory principle of this tendency is perhaps one of 'encoding economy': Intrinsic properties of events lead to more homogeneous ('natural') classes of events, and homogeneous or natural classes of events will occur more often in conversation than highly specific ones. The degree of homogeneity of an event description can thus be assumed to be reflected in lexicalization patterns, and we propose the following explanation:

\section{(46) The INTRINSICNESS-LEXICALIZATION HYPOTHESIS}

The more closely a parameter of event description interacts with the intrinsic properties of the event in question, the more often it will be encoded lexically, because lexical items tend to correspond to natural classes recurring in natural discourse, and events form natural classes on the basis of more intrinsic, rather than extrinsic, properties.

The second principle concerns the compatibility of events or event descriptions with specific types of modification. Manner predicates specify the internal organization of a given event. In order to be susceptible to such modification, there must be a certain flexibility for ways in which an event can take place. For example, a punctual event like an explosion does not lend itself to 'internal' modification; only the 'force' of the explosion provides some room for variability. An eating event, by contrast, implies a specific way of putting food into one's mouth, with or without biting, a specific way of chewing as well as relations between such sub-events (e.g. simultaneity vs. sequences). This type of 'internal complexity' leaves room for modification; one can eat noisily or quietly (in the 
chewing phase), one can chew with an open or closed mouth, one can eat fast or slowly (predicated of the chewing sub-events and the succession of swallowing sub-events), etc. This observation provides the basis of the explanation in (47):

\section{The PRINCIPLE OF MANNER-ModificATION}

Descriptions of complex events, i.e., descriptions of events comprising several (more or less clearly distinguishable) sub-events, lend themselves more to Manner modification because a higher number of sub-events (and relations between sub-events) implies a higher number of aspects of an event description to which Manner predicates can apply.

Finally, we have seen that there is at least one explanatory factor that is 'systemexternal', in the sense that it does not concern the relationship between form and meaning, but the relation between the speech community and the linguistic system. As has been pointed out, languages tend to encode the Motivation of a killing event to a greater extent than they encode the Motivation of any other event type that we have considered. This is intuitively plausible, as the Motivation of a killing event is an important piece of information, certainly much more important than the Motivation for cutting an onion or a piece of meat. As was stated in the 'Relevance-lexicalization principle', we assume that there is a tendency for languages to lexicalize those aspects of event descriptions that 'matter most' to a given speech community. This is perhaps a trivial finding; at the same time, however, it leads over to matters of linguistic relativity, a highly controversial and certainly non-trivial topic. The following formulation is an attempt to find a balance between a more or less trivial observation and a strong - linguistically relative - claim. It makes reference to Grice’s (1975) Cooperative Principle:

\section{THE PRINCIPLE OF RELEVANT LEXICALIZATION}

Languages tend to lexicalize those aspects of event descriptions which affect the social life of the relevant speech communities, because important information is frequently provided, in accordance with the Cooperative Principle, and thus tends to be conventionalized and lexicalized to

a greater extent than unimportant information.

While the three explanations given above emerged more or less directly from the generalizations made in Section 4.4, we would finally like to discuss an additional factor which has not been mentioned so far. It seems to us that the amount of information conveyed by a given parameter plays an important role in the probability of that parameter being lexicalized in a given language. A parameter 
can be assumed to be informative to the extent that it allows the hearer to make inferences about other parameters. Languages can be expected to lexicalize those parameters that allow speakers to make as many inferences as possible.

Let us illustrate this point with eating verbs. Given that eating is a rather heterogeneous activity, the (more) intrinsic properties of eating events are, to a considerable extent, a function of the (more) extrinsic properties. The type of food consumed (the Patient) is the most informative parameter, because it conveys information about the Manner of eating as well as the Agent, e.g. insofar as meat is consumed in a different way than soup, and insofar as humans tend to eat different things than animals (e.g. schnitzel with salad vs. raw meat). Depending on cultural differences, we can also expect specific types of food to be consumed at specific times of the day. It is thus not surprising to find that there is such enormous variation in the domain of eating verbs depending on the properties of the Patient.

While the fact that Patients are encoded prominently in eating events is not specific to that class of verbs, we have noticed that eating verbs, unlike all of the other classes considered in this study, sometimes also encode the Time of eating. This observation might be related to the fact that the Time of eating is also a relatively good predictor of other parameters, at least in European speech communities. Depending on the country or region, one can more or less safely predict what is eaten (the Patient) at specific times of the day. Note that the relevant verbs are also restricted to human Agents. The amount of information contained in a sentence like Bill is having breakfast is thus considerable - it tells us that Bill is a man (rather than a dog), that he is probably having coffee or tea with his meal, and - assuming that he lives in France - he is likely to have a baguette on his table.

\section{Summary and conclusion}

Building on earlier contrastive and cross-linguistic work (e.g. Leisi 1971, Plank 1984) and more recent theoretical studies, especially those by Rappaport Hovav \& Levin (2010), we hope to have made some new observations on differences in the lexical inventories of different languages for the notional domains under investigation, i. e., descriptions of events of eating and drinking, and of physical impact (killing, beating, cutting). What are the general conclusions we can draw from the preceding comparative observations? 
The first conclusion is that the semantic parameters differentiating between similar lexical items and similar lexical inventories differ in many more and much more subtle ways than we find in comparing grammatical items. It is for this reason that lexical typology is so much more difficult than morpho-syntactic typology. Still, we have noted that specific dimensions of variation - those relating to restrictions on, or the encoding of, participant relations, temporal and locative specifications as well as the Manner and Result of an action - allow for certain generalizations. In particular, we have proposed hierarchies ranking pairs of event parameters which make similar contributions to the meaning of a sentence. Thus we found that all types of verbs considered in our study tend to encode aspects of the Patient to a greater extent than those of the Agent, that the lexicalization of the Manner and Instrument seems to be more common than that of Time and Place (in the event types investigated by us), and that there are differences, in particular, between the relative rankings of Manner and Instrument, depending on the specific verb class investigated.

A second and probably not totally unexpected finding is that languages may differ strikingly in the differentiations they manifest. There are only few verbs of eating and drinking in most European languages, but there seem to be many such verbs in Polynesian languages. A similar contrast is found with respect to verbs of cutting; there are few such verbs in the European languages considered, but a wide variety of them is found in Oceanic languages. We have not discussed any explanations for these differences, and we have refrained from making a point for linguistic relativity in this context. While it is tempting to assume that speech communities with a broader range of dishes will make more relevant distinctions in the verbal lexicon, we are fully aware that such claims are easily falsified, e.g. when speech communities with similar eating and dressing habits differ considerably in their lexical inventories. As has been shown by Plank (1984), English uses only two very general terms for putting on or taking off clothes and accessories, while German has a wide variety of very specific terms depending on the garment or accessory and their contact with the body. Does that mean that Germans pay more attention to their clothes than Englishmen do? It certainly does not.

Even so, we have proposed one explanation that makes reference to habits of a speech community, i. e., the special status of verbs of killing. Killing is such a dramatic action for any speech community, and it is likely to be evaluated in such different ways depending on the Motivations of that action - killing can make one 
a hero (in war), or result in the loss of one's live (in the case of murder) - that we can expect the Motivation of a killing event to figure prominently in descriptions of the relevant actions.

In addition to that 'system-external', perhaps partly relativistic, explanation, we have proposed three 'system-internal' explanations, all of which could be regarded as boiling down to matters of economy in the relationship between form and function. First, we have argued that the degree of 'intrinsicness' of an event parameter correlates positively with the probability of that property being encoded lexically, as intrinsic aspects of event descriptions can be assumed to lead to natural classes more easily than extrinsic ones (for instance, it is more likely to find a specialized lexical item for 'raining heavily' than for 'raining in Spain'). Second, we have pointed out that the internal organization of an event - its degree of complexity - has implications for the likelihood with which that event will be modified by a Manner specification. The more 'sub-aspects' there are of a given event, the more Manner specifications are conceivable. Finally, we have argued that 'informativeness' may play a role, and that languages tend to encode those parameters lexically that allow hearers to make inferences about other parameters.

We are fully aware that the observations and suggestions made in this study are tentative, which is why we have added the hedge 'programmatic' to the title of this contribution. We have proposed a framework allowing for the formulation of generalizations by ranking pairs of event parameters, based on a NeoDavidsonian event semantics, hoping that this method will prove useful for further, more comprehensive, typologies of event descriptions.

\section{Bibliography}

Alexiadou, A. \& E. Anagnostopoulou. 2013. Manner vs. result complementarity in verbal alternations: A view from the clear alternation. In NELS, vol. 42, 39-52.

Beavers, J. \& A. Koontz-Garboden. 2012. Manner and result in the roots of verbal meaning. Linguistic Inquiry 43. 331-369.

Beavers, J., B. Levin \& Shiao Wei Tham. 2010. The typology of motion events revisited. Journal of Linguistics 46. 331-377.

Berlin, B. \& P. Kay. 1969. Basic color terms. Their universality and evolution. Berkeley, California: University of California Press.

Cruse, D. A. 1986. Lexical semantics. Cambridge: Cambridge University Press. 
Dik, S. 1997. The theory of functional grammar. Berlin/New York: Mouton de Gruyter.

Du Bois, J. 1985. Competing motivations. In J. Haiman (ed.), Iconicity in syntax, 343-365. John Benjamins.

Evans, N. 2011a. Anything can happen. In N. Thieberger (ed.), The Oxford handbook of linguistic fieldwork, 183-208. Oxford: Oxford University Press.

Evans, N. 2011b. Semantic typology. In J. J. Song (ed.), The Oxford handbook of linguistic typology, 504-533. Oxford: Oxford University Press.

Grice, H. P. 1975. Logic and conversation. In P. Cole \& J. Morgan (eds.), Speech acts (syntax and semantics 3), 41-58. New York: Academic Press.

Husband, E. M. 2011. Rescuing manner/result complementarity from certain death. In Proceedings of CLS 47.

Koch, P. 2001. Lexical typology. In M. Haspelmath, E. König, W. Oesterreicher $\&$ W. Raible (eds.), Language typology and language universals: An international handbook, 1142-1178. Berlin: Mouton de Gruyter.

Kratzer, A. 1996. Severing the external argument from the verb. In J. Rooryck \& L. Zaring (eds.), Phrase structure and the lexicon, 109-137. Dordrecht: Kluwer.

Leisi, E. 1971. Der Wortinhalt. Seine Struktur im Deutschen und Englischen. Heidelberg: UTB.

Levin, B. 1993. English verb classes and alternations: A preliminary investigation. Chicago: University of Chicago Press.

Levin, B. \& M. Rappaport Hovav. 1991. Wiping the slate clean: A lexical semantic exploration. Cognition 41. 123-151.

Levin, B. \& M. Rappaport Hovav. 2006. Constraints on the complexity of verb meaning and VP structure. In H.-M. Gärtner, R. Eckardt, R. Musan \& B. Stiebels (eds.), Between 40 and 60 puzzles for Krifka, ZAS Berlin.

Levin, B. \& M. Rappaport Hovav. 2013. Lexicalized meaning and manner/result complementarity. In B. Arsenijević, B. Gehrke \& R. Marín (eds.), Studies in the composition and decomposition of event predicates, 49-70. Dordrecht: Springer.

Lyons, J. 1972. Structural semantics: An analysis of part of the vocabulary of Plato. London: Basil Blackwell.

Löbner, S. 2002. Understanding semantics. London: Arnold.

Löbner, S. 2011. Concept types and determination. Journal of Semantics 28 (3). 279-333.

Majid, A. \& M. Bowerman (eds.). 2007. Cutting and breaking events: A crosslinguistic perspective. Special issue of Cognitive Linguistics 18.2. 
Majid, A., M. Bowerman, M. van Staden \& J. S. Boster. 2007. The semantic categories of cutting and breaking events: A cross-linguistic perspective. Cognitive Linguistics 18.2. 133-152.

Moyse-Faurie, C. 1993. Dictionnaire futunien-français. Langues et cultures du Pacifique 8. Leuven: Peeters-Selaf.

Moyse-Faurie, C. 1995. Le xârâcùù, langue de Thio-Canala (Nouvelle-Calédonie). Éléments de syntaxe. Langues et Cultures du Pacifique 10. Leuven: Peeters-Selaf. Moyse-Faurie, C. \& M.-A. Néchérö-Jorédié. 1986. Dictionnaire xârâcùù-français, (Nouvelle-Calédonie). Nouméa: Édipop. (1989: 2ème éd.).

Naess, Å. 2011. The grammar of eating and drinking verbs. Language and Linguistics Compass 5/6. 413-423.

Narasinhan, B., A. Kopecka, M. F. Bowerman, M. Gullberg \& Asifa M. 2012. Putting and taking events: A cross-linguistic perspective. In B. Narasinhan \& A. Kopecka (eds.), Events of 'putting' and 'taking': A cross-linguistic perspective, 1-18. Amsterdam: Benjamins.

Ozanne-Rivierre, F. \& J.-C. Rivierre. 2004. Verbal compounds and lexical prefixes in the languages of New Caledonia. In I. Bril \& F. Ozanne-Rivierre (eds.), Complex predicates in Oceanic languages: Studies in the dynamics of binding and boundedness, 347-371. Berlin: Mouton de Gruyter.

Parsons, T. 1990. Events in the semantics of English. A study in subatomic semantics. Cambridge/Mass.: MIT Press.

Plank, F. 1984. Verbs and objects in semantic agreement: Minor differences between English and German that might suggest a major one. Fournal of Semantics 3. 305-360.

Putnam, M. \& V. Gast. 2012. The syntax and semantics of excess: over-predicates in Germanic. In J. Choi, E. A. Hogue, J. Punske, D. Tat, J. Schertz \& A. Trueman (eds.), Proceedings of WCCFL 29, 223-231. Somerville, MA: Cascadilla Press.

Rappaport Hovav, M. \& B. Levin. 2010. Reflections on manner/result complementarity. In E. Doron, M. Rappaport Hovav \& I. Sichel (eds.), Syntax, lexical semantics, and event structure, 21-38. Oxford: Oxford University Press.

Rice, S. 2009. Athabascan eating and drinking verbs and constructions. the linguistics of eating and drinking. In J. Newman (ed.), The linguistics of eating and drinking, 109-52. Amsterdam: Benjamins.

Talmy, L. 1985. Lexicalization patterns: Semantic structure in lexical forms. In T. Shopen (ed.), Language typology and description, vol. 3: Categorization and the lexicon, 57-149. Cambridge: Cambridge University Press.

Talmy, L. 2000. Toward a cognitive semantics. Cambridge, MA: MIT Press. 
Van Valin, R. D. Jr \& R. LaPolla. 1997. Syntax: structure, meaning and function. Cambridge: Cambridge University Press.

Wierzbicka, A. 2009. All people eat and drink. Does this mean that 'eating' and 'drinking' are universal human concepts? In J. Newman (ed.), The linguistics of eating and drinking, 65-89. Amsterdam: Benjamins.

\section{Authors}

Volker Gast

Department of English and American Studies

Friedrich-Schiller-Universität Jena

Volker.Gast@uni-jena.de

Ekkehard Koenig

Freie Universität Berlin \& Albert-Ludwigs-Universität Freiburg koenig@zedat.fu-berlin.de

Claire Moyse

CNRS, LACITO (Langues et Cultures à Tradition Orale)

Villejuif, France

moyse@vjf.cnrs.fr 
